\title{
Pain Interference and Decreased Physical Function After Emergency General Surgery: Measuring Patient-Reported Outcomes
}

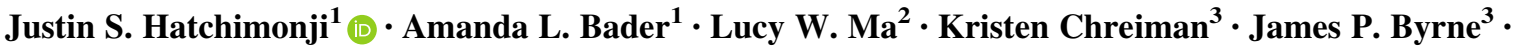 \\ Patrick M. Reilly ${ }^{3} \cdot$ Benjamin M. Braslow $^{3} \cdot$ Mark J. Seamon ${ }^{3} \cdot$ Daniel N. Holena $^{3,4}$
}

Accepted: 7 February 2021/Published online: 8 March 2021

(C) Société Internationale de Chirurgie 2021

\begin{abstract}
Introduction There is increasing emphasis on patient-reported outcomes (PROs) measures in healthcare, but this area remains largely unexplored in emergency general surgery (EGS) conditions. We hypothesized that postoperative patients in our EGS clinic would report detrimental changes in several domains of health-related quality of life (HRQoL).

Methods We administered the PROMIS-29, a HRQoL measurement tool, to postoperative patients in our EGS clinic (11/2019-4/2020). Patients responded to measures of 7 domains. Domain scores were converted to t-scores, allowing comparison to average values within the general US population (set to 50 by definition). We report the mean scores within each domain. Higher scores in negatively worded domains (e.g., "Depression") are worse; vice versa for positively worded domains (e.g., "Physical Function"). Changes in scores at subsequent clinic visits were analyzed using the paired t-test.

Results There were 97 patients who completed the PROMIS-29 at the first postoperative visit. Mean (SD) age was 54.1 (16.2) years; $51 \%$ were male. There was no difference in our patients from the average US population in the domains of Ability to Participate in Social Roles and Activities, Anxiety, Fatigue, and Sleep Disturbance. However, EGS patients experienced significantly greater Pain Interference $(56.1[54.1,58.1])$ and worse Physical Function $(40.6[38.4,42.7])$ than average. For patients seen in follow-up twice (13 patients, median interval between clinic visits 21 days), there were improvements in the domains of Physical Function (42.9 vs 37.3; $p=0.04)$ and Fatigue. Conclusion We demonstrate room for improvement in the domains of pain interference and physical function. While positive changes over a relatively short period of time are encouraging, consideration should be given to patient perceptions of illness and lifestyle impact when managing EGS patients.
\end{abstract}

Justin S. Hatchimonji

justin.hatchimonji@pennmedicine.upenn.edu

Amanda L. Bader

amanda.bader@pennemedicine.upenn.edu

Lucy W. Ma

lucywma@sas.upenn.edu

Kristen Chreiman

kristen.chreiman@pennmedicine.upenn.edu

James P. Byrne

james.byrne@pennmedicine.upenn.edu
Patrick M. Reilly

reillyp@uphs.upenn.edu

Benjamin M. Braslow

benjamin.braslow@pennmedicine.upenn.edu

Mark J. Seamon

mark.seamon@pennmedicine.upenn.edu

Daniel N. Holena

holenad@pennmedicine.upenn.edu

1 Department of Surgery, Perelman School of Medicine at the University of Pennsylvania, 3400 Spruce St, 4 Maloney, Philadelphia, PA, USA 


\section{Background}

Though the formal collection of data on patients' healthrelated quality of life (HRQoL) began in the 1960s [1], the majority of interest in HRQoL and patient-reported outcomes (PROs) measures has come about in the more recent past. The 2001 Institute of Medicine report "Crossing the Quality Chasm" [2] recommended allotting a greater amount of control to patients in making healthcare decisions [3]; soon thereafter, this was followed by the creation of the Patient-Centered Outcomes Research Institute (PCORI), PRO reporting guidelines from the National Quality Forum (NQF) [4], and the inception of the PatientReported Outcomes Measurement Information System (PROMIS), funded by the National Institutes of Health (NIH) [5]. The latter was created in an effort to create a standardized and centralized resource amid a growing variety of resources [1].

Despite these initiatives, surgical specialties have lagged behind. Only recently has evidence been generated in specialties such as urology [6,7], cardiac surgery [8], and trauma $[9,10]$, as well as a variety of other surgical subspecialties [11-17]. Study of PROs in general surgery has been minimal [18]; indeed, a recent scoping review of literature describing the use of PROMIS instruments in surgery found that only three out of 21 studies were in general surgery populations [1].

Furthermore, the literature lacks data on PROs in emergency general surgery (EGS), which is distinct from elective surgery not only in its unplanned nature, but in that EGS patients suffer increased morbidity and mortality [19-21]. Given these increased rates and the fact that $25 \%$ of the 3 million admitted EGS patients per year will require an emergent operation [22, 23], measurement of PROs in patients experiencing these potentially life-altering admissions would seem logical. As physicians, goals of treatment should extend beyond a discharge from the hospital alive. Simple assessment of HRQoL has been shown to increase patient-physician communication [24]. Beyond this, the results of such an assessment can inform the efforts of surgeons and their teams to improve outcomes that are important to patients. In order to begin to improve these outcomes, they must first be accurately measured.

2 School of Arts and Sciences, University of Pennsylvania, Philadelphia, PA, USA

3 Division of Traumatology, Emergency Surgery, and Surgical Critical Care, Perelman School of Medicine at the University of Pennsylvania, Philadelphia, PA, USA

4 Center for Clinical Epidemiology and Biostatistics, Perelman School of Medicine at the University of Pennsylvania, Philadelphia, PA, USA
In this study, we investigated self-reported HRQoL outcomes for follow-up EGS patients. We hypothesized that given the high morbidity rates in EGS, these patients would report poor outcomes in several domains of HRQoL.

\section{Methods}

We collected patient-reported outcomes data from followup EGS patients in our outpatient office from November 2019 through April 2020. While waiting to be evaluated, all post-discharge patients were asked to self-administer the PROMIS-29 v2.0 instrument on a tablet device after receiving instruction from trained medical assistants. The PROMIS instruments are made publicly available by the National Institutes of Health (NIH), extensively validated $[25,26]$, and similar to the 36-Item Short Form Survey (SF-36) [27]. The PROMIS-29 surveys 8 domains: Participation in Social Roles/Activities, Anxiety, Depression, Fatigue, Pain Interference, Physical Function, Sleep Disturbance, and Pain Intensity. Pain Intensity is scored on a 10-point scale. Each of the remaining domains contains 4 items, scored on a 5-point scale. These ask more detailed questions regarding the impact of illness on the patient's daily life. For example, the "Pain Interference" domain asks patients to rate the degree to which pain interferes with (1) day to day activities, (2) work around the home, (3) the ability to participate in social activities, and (4) household chores. The full instrument is shown in Table 1 [5].

Our institution's electronic health record (EHR) was reviewed for demographic, procedure, and length of stay (LOS) data on patients who completed the PROMIS-29. Collected data included age, sex, admission and discharge dates, number of intensive care unit (ICU) days, nature of operation or lack thereof, transfer status, and whether or not the admission in question was a readmission. Readmission was defined as an admission within 30 days of a surgical procedure. Patients who were being seen in clinic preoperatively for an elective operation, were more than 1 year remove from the index operation, or were being seen in follow-up for an operation performed at another hospital were excluded (Fig. 1).

First, a descriptive analysis of the cohort was performed. We reported values as mean (standard deviation [SD]), number (\%), or median (interquartile range [IQR]), as appropriate. PROMIS scores are standardized to a reference population; in the case of all PROMIS-29 domains except for Pain Intensity, the reference is the US population. As such, patient scores are translated to t-scores per a 
Table 1 Elements of the PROMIS-29 Profile v2.0 [5]. Five potential answer choices, corresponding to Likert scales, are provided with each question. Wording of these answer choices varies by domain and is displayed

\begin{tabular}{|c|c|c|c|c|c|c|}
\hline$\frac{\text { Domain }}{\text { Physical function }}$ & $\begin{array}{l}\text { Questions } \\
\text { Are you able to do chores such as vacuuming or } \\
\text { yard work? }\end{array}$ & \multicolumn{5}{|c|}{ Answer choices } \\
\hline Physical function & $\begin{array}{l}\text { Are you able to do chores such as vacuuming or } \\
\text { yard work? } \\
\text { Are you able to go up and down stairs at a normal } \\
\text { pace? } \\
\text { Are you able to go for a walk of at least } 15 \text { min? } \\
\text { Are you able to run errands and shop? }\end{array}$ & $\begin{array}{l}\text { Without any } \\
\text { difficulty }\end{array}$ & $\begin{array}{l}\text { With a little } \\
\text { difficulty }\end{array}$ & $\begin{array}{l}\text { With some } \\
\text { difficulty }\end{array}$ & $\begin{array}{l}\text { With much } \\
\text { difficulty }\end{array}$ & $\begin{array}{l}\text { Unable } \\
\text { to do }\end{array}$ \\
\hline \multirow[t]{2}{*}{ Anxiety } & In the past 7 days... & & & & & \\
\hline & $\begin{array}{l}\text { I felt fearful } \\
\text { I found it hard to focus on anything other than my } \\
\text { anxiety } \\
\text { My worries overwhelmed me } \\
\text { I felt uneasy }\end{array}$ & Never & Rarely & Sometimes & Often & Always \\
\hline \multirow[t]{2}{*}{ Depression } & In the past 7 days... & & & & & \\
\hline & $\begin{array}{l}\text { I felt worthless } \\
\text { I felt helpless } \\
\text { I felt depressed } \\
\text { I felt hopeless }\end{array}$ & Never & Rarely & Sometimes & Often & Always \\
\hline \multirow[t]{2}{*}{ Fatigue } & $\begin{array}{l}\text { During the past } 7 \text { days... } \\
\text { I feel fatigued } \\
\text { I have trouble starting things because I am tired } \\
\text { In the past } 7 \text { days... }\end{array}$ & Not at all & A little bit & Somewhat & Quite a bit & $\begin{array}{l}\text { Very } \\
\text { much }\end{array}$ \\
\hline & $\begin{array}{l}\text { How run-down did you feel on average? } \\
\text { How fatigued were you on average? }\end{array}$ & Not at all & A little bit & Somewhat & Quite a bit & $\begin{array}{l}\text { Very } \\
\text { much }\end{array}$ \\
\hline \multirow[t]{2}{*}{ Sleep disturbance } & $\begin{array}{l}\text { In the past } 7 \text { days... } \\
\text { My sleep quality was } \\
\text { In the past } 7 \text { days... }\end{array}$ & Very poor & Poor & Fair & Good & $\begin{array}{l}\text { Very } \\
\text { good }\end{array}$ \\
\hline & $\begin{array}{l}\text { My sleep was refreshing } \\
\text { I had a problem with my sleep } \\
\text { I had difficulty falling asleep }\end{array}$ & Not at all & A little bit & Somewhat & Quite a bit & $\begin{array}{l}\text { Very } \\
\text { much }\end{array}$ \\
\hline $\begin{array}{l}\text { Ability to participate in social } \\
\text { roles and activities }\end{array}$ & $\begin{array}{l}\text { I have trouble doing all of my regular leisure } \\
\text { activities with others } \\
\text { I have trouble doing all of the family activities that } \\
\text { I want to do } \\
\text { I have trouble doing all of my usual work (include } \\
\text { work at home) } \\
\text { I have trouble doing all of the activities with friends } \\
\text { that I want to do }\end{array}$ & Never & Rarely & Sometimes & Usually & Always \\
\hline \multirow[t]{2}{*}{ Pain interference } & In the past 7 days... & & & & & \\
\hline & $\begin{array}{l}\text { How much did pain interfere with your day to day } \\
\text { activities? } \\
\text { How much did pain interfere with work around the } \\
\text { home? } \\
\text { How much did pain interfere with your ability to } \\
\text { participate in social activities? } \\
\text { How much did pain interfere with your household } \\
\text { chores? }\end{array}$ & Not at all & A little bit & Somewhat & Quite a bit & $\begin{array}{l}\text { Very } \\
\text { much }\end{array}$ \\
\hline \multirow[t]{2}{*}{ Pain intensity } & $\begin{array}{l}\text { In the past } 7 \text { days... } \\
\text { How would you rate your pain on average? }\end{array}$ & \multicolumn{5}{|c|}{$0-1-2-3-4-5-6-7-8-9-10$} \\
\hline & & & No pain & Worst is & aginable pain & \\
\hline
\end{tabular}


Fig. 1 Inclusions and exclusions. PROMIS Patient-

Reported Outcomes

Measurement Information

System

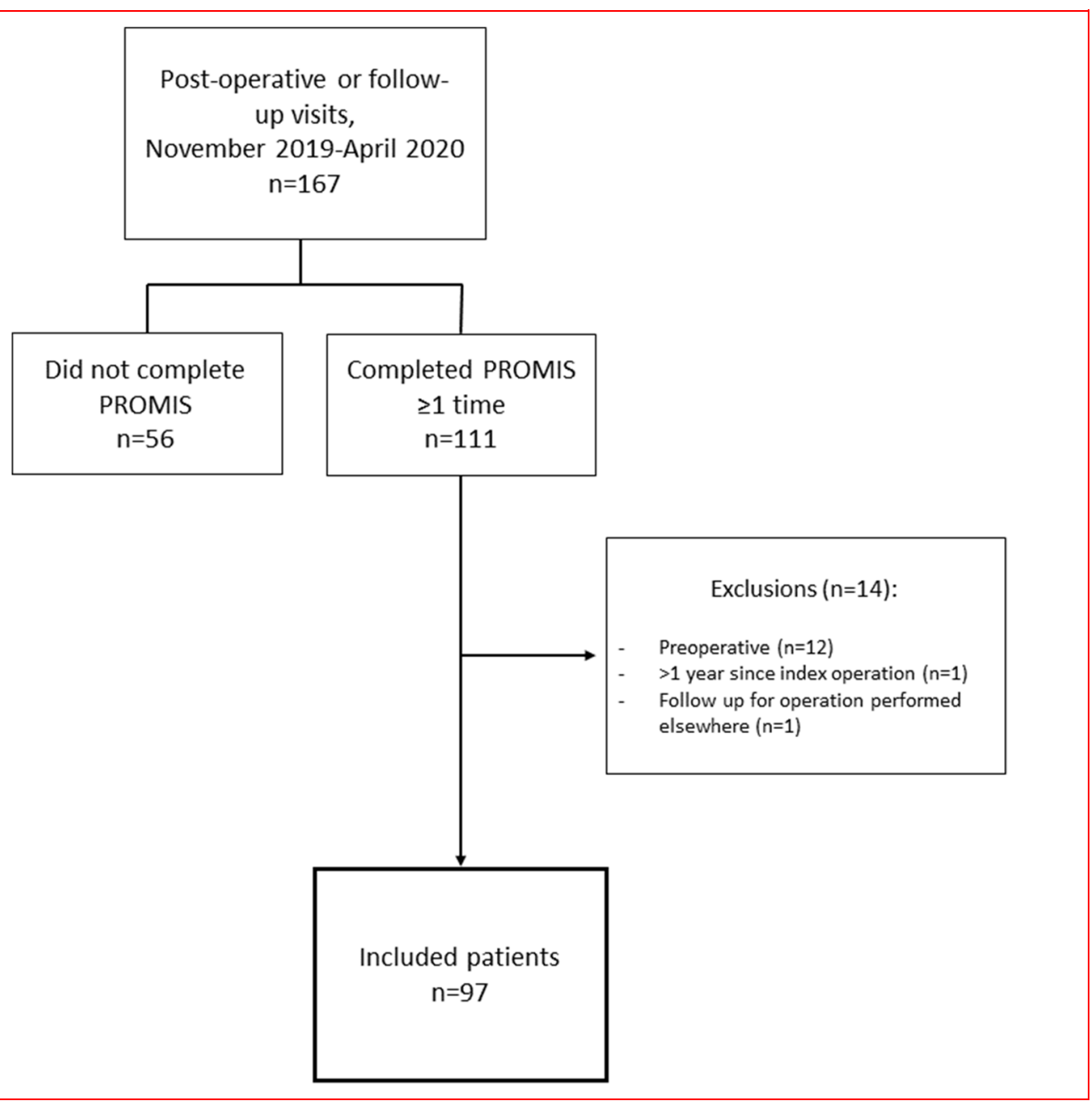

table provided with the instrument [5]. Standardized scores in the reference population are normally distributed with an average of 50 and standard deviation of 10 . We report aggregate scores for our cohort as means (SD). Higher scores are worse in the domains of Anxiety, Depression, Fatigue, Pain Interference, Pain Intensity, and Sleep Disturbance, while lower scores are worse in Ability to Participate in Social Roles and Activities and Physical Function. Mean and distribution curves for each domain were plotted for our cohort and compared to the population distribution. Repeated scores among patients who completed the questionnaire at a second follow-up visit were analyzed using paired t-tests in all domains except for pain intensity, for which we used a Wilcoxon signed-rank test given a non-normal distribution. Three patients completed the PROMIS-29 a third time and 1 patient completed it a fourth time; these data were not included due to lack of generalizability and interpretability.

This study was determined by our center's Institutional Review Board to be exempt from review. All statistical analyses were performed using Stata version 15.1 (College Station, TX).

\section{Results}

One hundred and sixty-seven emergency general surgery patients were seen in clinic during this time period; 111 of whom completed the PROMIS-29 at least once. After exclusions, we were left with 97 subjects in the overall cohort, 13 of whom completed the questionnaire more than once. Mean (SD) age was 54.1 (16.2) years, approximately half were female, the majority $(78 \%)$ underwent an operation, and $26 \%$ were transfer patients from another hospital (Table 2).

Patients present to clinic for follow-up a median of 16 days (IQR 11, 30) following discharge. At this time point, they reported a median $[\mathrm{IQR}]$ pain score (on a scale of $0-10$, with 10 being the worst) of $3[1,5]$. Mean values for many of the remaining 7 domains were not significantly different than the US population average. However, 
Table 2 Demographic and admission characteristics, EGS patients completing PROMIS-29 at follow-up

\begin{tabular}{lll}
\hline Patient or admission characteristic & Overall cohort $(n=97)$ & Completed PROMIS-29 twice $(n=13)$ \\
\hline Age (years), mean (SD) & $54.1(16.2)$ & $59.2(13.1)$ \\
Female, n (\%) & $48(49 \%)$ & $6(46 \%)$ \\
Hospital LOS (days), median (IQR) & $5(1,12)$ & $19(9,22)$ \\
ICU days, median (IQR) & $0(0,2)$ & $2(0,13)$ \\
Operative management, n (\%) & $76(78 \%)$ & $13(100 \%)$ \\
Laparoscopic appendectomy & $11(11 \%)$ & $0(0 \%)$ \\
Laparoscopic cholecystectomy & $14(14 \%)$ & $0(0 \%)$ \\
Hernia repair (inguinal or ventral) & $9(9 \%)$ & $0(0 \%)$ \\
Laparotomy & $20(21 \%)$ & $6(46 \%)$ \\
Other & $22(23 \%)$ & $7(54 \%)$ \\
Transfer from another facility, $n(\%)$ & $25(26 \%)$ & $4(31 \%)$ \\
\hline
\end{tabular}

$S D$ standard deviation; $L O S$ length of stay; $I Q R$ interquartile range; $I C U$ intensive care unit

Table 3 Mean domain scores at first questionnaire administration

\begin{tabular}{llr}
\hline Domain & Mean t-score & 95\% CI \\
\hline Ability to participate in social roles and activities & 49.1 & $46.6,51.5$ \\
Anxiety & 50.8 & $48.7,52.8$ \\
Depression & 48.2 & $46.4,50.0$ \\
Fatigue & 50.9 & $48.6,53.2$ \\
Pain interference* & 56.1 & $54.1,58.1$ \\
Physical function* & 40.6 & $38.4,42.7$ \\
Sleep disturbance & 48.7 & $46.6,50.8$ \\
\hline
\end{tabular}

Higher scores are worse in anxiety, depression, fatigue, pain interference, and sleep disturbance; lower scores are worse in ability to participate in social roles and activities, physical function. By definition, population mean is 50 . Domains in which mean values are significantly different than population average are designated by bold font and asterisk $(*)$

CI confidence interval

patients did report worse pain interference (mean t-score $56.1,95 \%$ CI 54.1, 58.1) and physical function (mean t-score 40.6, 95\% CI 38.4, 42.7) at this time point (Table 3). Distribution curves are shown in Fig. 2. A subset analysis of only those patients who underwent an operation $(n=76)$ yielded similar results, with worse outcomes in the same two domains as the overall cohort. Of note, a significant proportion of these patients had undergone relatively minor operations (30 laparoscopic operations, 9 hernia repairs). An examination of only those patients who had undergone laparotomy $(n=20)$ again yielded results similar to the overall cohort (Table 4). Again, scores in the physical function and pain interference domains were significantly different than the US average. Median [IQR] pain intensity score was also similar at $3[1,5.5]$.
There were 13 patients who presented for a second follow-up visit and completed the PROMIS-29. The median (IQR) time between the first visit and the second was 21 $(14,28)$ days. Regarding the domains in which mean values were worse than the US average at time 1, there was no statistically significant improvement in pain interference over time (mean t-score 55.7 at time 1 versus 50.6 at time $2, p=0.160$. There was a significant improvement in physical function (37.3 at time 1 versus 42.9 at time 2; $p=0.043$ ), but this continued to be worse than average. There was an additional significant improvement in fatigue, which was better than the US average at the second time point (mean 42.6, 95\% CI 37.1, 48.0) (Table 5) (Fig. 3). Of note, all of these patients had undergone an operation, 6/13 $(46.2 \%)$ of them had undergone a laparotomy, and 7/13 $(53.8 \%)$ had been admitted to the ICU (Table 2). 

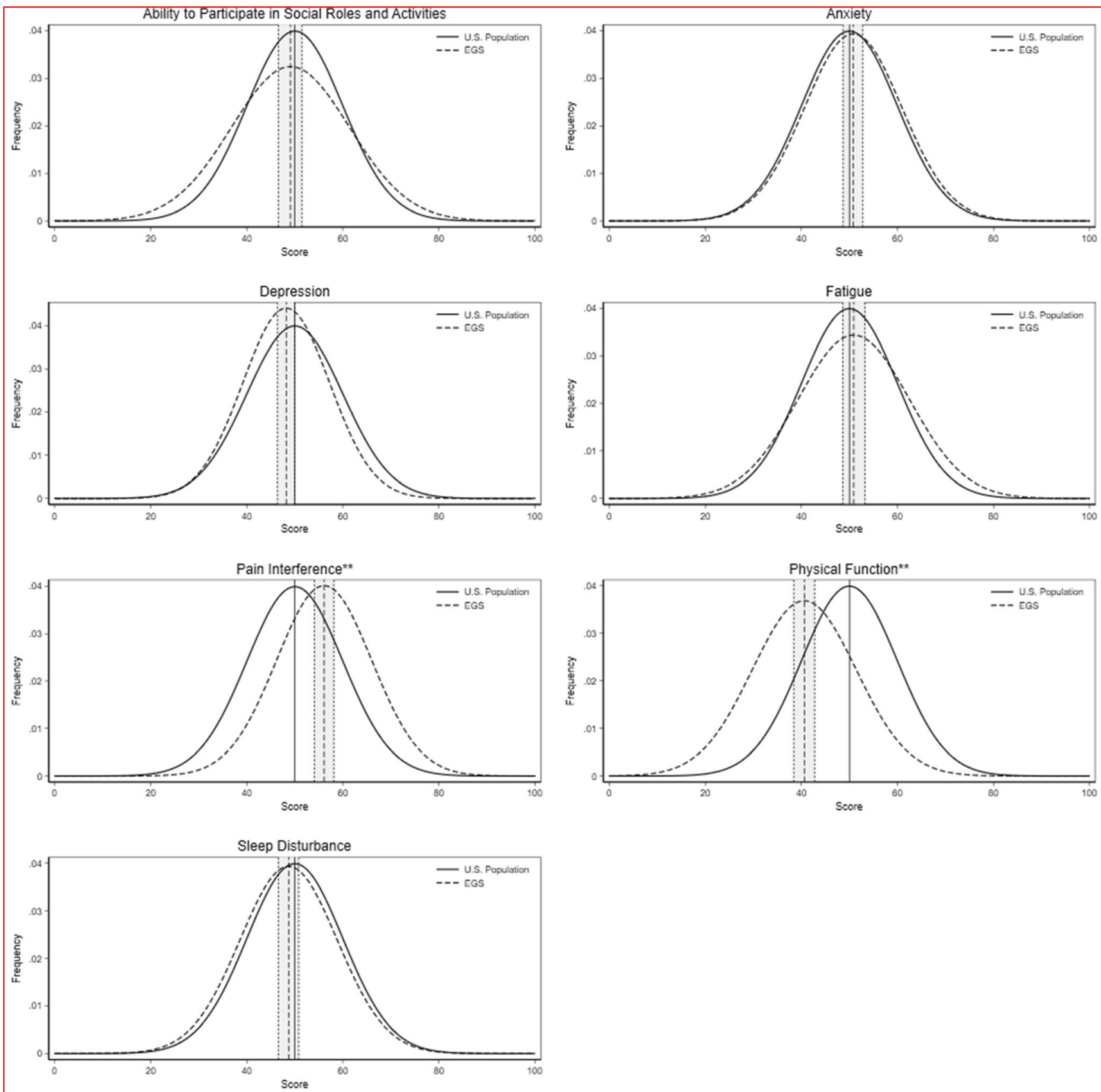

Fig. 2 Distributions of EGS patients versus US population, by PROMIS domain. Dashed curves and reference lines represent EGS; solid lines represent population. Shaded area represents $95 \%$ CI for mean among EGS patients. **Denotes domains in which mean in EGS differs significantly from comparison population. EGS emergency general surgery; PROMIS Patient-Reported Outcomes Measurement Information System; $C I$ confidence interval

\section{Discussion}

In this study, we used the PROMIS-29 instrument to evaluate patient-reported HRQoL outcomes in post-discharge EGS patients, hypothesizing that these patients would display poor outcomes in HRQoL. We found that while patients were on par with the US average in several domains, they did report significant pain interference and decreased physical function. Overall pain intensity following hospital discharge was mild. In the subset of patients completing the questionnaire at a subsequent follow-up visit, there were significant improvements in 
Table 4 Mean domain scores at first questionnaire administration, laparotomies only $(n=-20)$

\begin{tabular}{llr}
\hline Domain & Mean t-score & 95\% CI \\
\hline Ability to participate in social roles and activities & 44.4 & $38.7,50.2$ \\
Anxiety & 53.8 & $48.6,59.0$ \\
Depression & 49.0 & $44.9,53.0$ \\
Fatigue & 53.5 & $48.5,58.4$ \\
Pain interference* & 56.7 & $52.7,60.7$ \\
Physical function* & 36.8 & $32.4,41.1$ \\
Sleep disturbance & 50.1 & $46.0,54.1$
\end{tabular}

Higher scores are worse in anxiety, depression, fatigue, pain interference, and sleep disturbance; lower scores are worse in ability to participate in social roles and activities, physical function. By definition, population mean is 50. Domains in which mean values are significantly different than population average are designated by bold font and asterisk $(*)$

CI confidence interval

Table 5 Repeated measures, PROMIS-29, in patients who completed the questionnaire twice $(n=13)$

\begin{tabular}{|c|c|c|c|c|c|}
\hline Domain & Mean, time 1 & CI, time 1 & Mean, time 2 & CI, time 2 & p-value \\
\hline Ability to participate in social roles and activities & 46.0 & $38.7,53.3$ & 52.8 & $47.0,58.6$ & 0.101 \\
\hline Anxiety & 51.4 & $45.3,57.5$ & 46.0 & $41.7,50.3$ & 0.065 \\
\hline Depression & 49.0 & $43.9,54.1$ & 45.9 & $41.6,50.2$ & 0.090 \\
\hline Fatigue* & 53.6 & $47.5,59.6$ & 42.6 & $37.1,48.0$ & 0.003 \\
\hline Pain interference & 55.7 & $50.2,61.1$ & 50.6 & $44.7,56.5$ & 0.160 \\
\hline Physical function* & 37.3 & $32.5,42.1$ & 42.9 & $36.9,48.9$ & 0.043 \\
\hline \multirow[t]{2}{*}{ Sleep disturbance } & 48.3 & $43.0,53.6$ & 44.2 & $39.0,49.5$ & 0.141 \\
\hline & Median, time 1 & IQR, time 1 & Median, time 2 & IQR, time 2 & $p$-value \\
\hline Pain intensity & 3 & 1,5 & 2 & 0,5 & 0.456 \\
\hline
\end{tabular}

Differences tested using paired t-test, except for pain intensity, which was tested using the Wilcoxon signed-rank test. Median time between tests: 21 days. Pain intensity rated on 10-point scale; remainder of domains expressed as t-scores with mean $=50$ and SD $=10$. Domains with a significant change in mean or median score designated with bold font and asterisk $(*)$

SD standard deviation; CI confidence interval; PROMIS Patient-Reported Outcomes Measurement Information System

physical function and fatigue. While the results of the initial administration of the questionnaire confirm our hypothesis, the improvement at the second time point is encouraging.

To our knowledge, this is the first study of patient-reported HRQoL outcomes in EGS patients. As noted, there has been some investigation into subspecialty populations and trauma, but almost none in general surgery [1]. Several of these studies have demonstrated decreased HRQoL postoperatively or post-discharge [9, 14]. This finding depends on the nature of operation, however. Breast reconstruction [12] and bariatric surgery [16] patients have shown improvement postoperatively. The existing literature is heterogeneous; while one may extrapolate some of it to an extent, EGS is a distinct population for which this study adds evidence to the literature.

This prospective study represents Level II evidence [28]. Strengths include a significant effect size and data collection over multiple time points. There are limitations to address, however. After exclusion of 14 patients, our questionnaire completion rate was $97 / 153=63.4 \%$. We did not evaluate those who did not complete the PROMIS29 for possible exclusion criteria; therefore, the denominator is likely smaller and our rate likely slightly better. Nonetheless, there is the potential for selection bias if there was systematic difference between those who completed the survey and those who did not. Beyond this, it is unclear how many of our patients present to clinic for follow-up, or how many are missed entirely because they are lost to follow-up. The high proportion of appendectomy and cholecystectomy patients in our cohort also warrants discussion, as we suspect these patients would have the lowest morbidity and mortality. While these are bona fide EGS operations that deserve consideration, the high proportion of these patients may obscure the decreased HRQoL experienced by our more complex or chronic EGS patients. 
Fig. 3 PROMIS scores over time, among patients completing the questionnaire twice $(n=13)$. Median time between tests: 21 days. t-score of 50 represents average in the US population. Asterisks *designate domains in which a significant change was observed between time points. $C I$ confidence interval

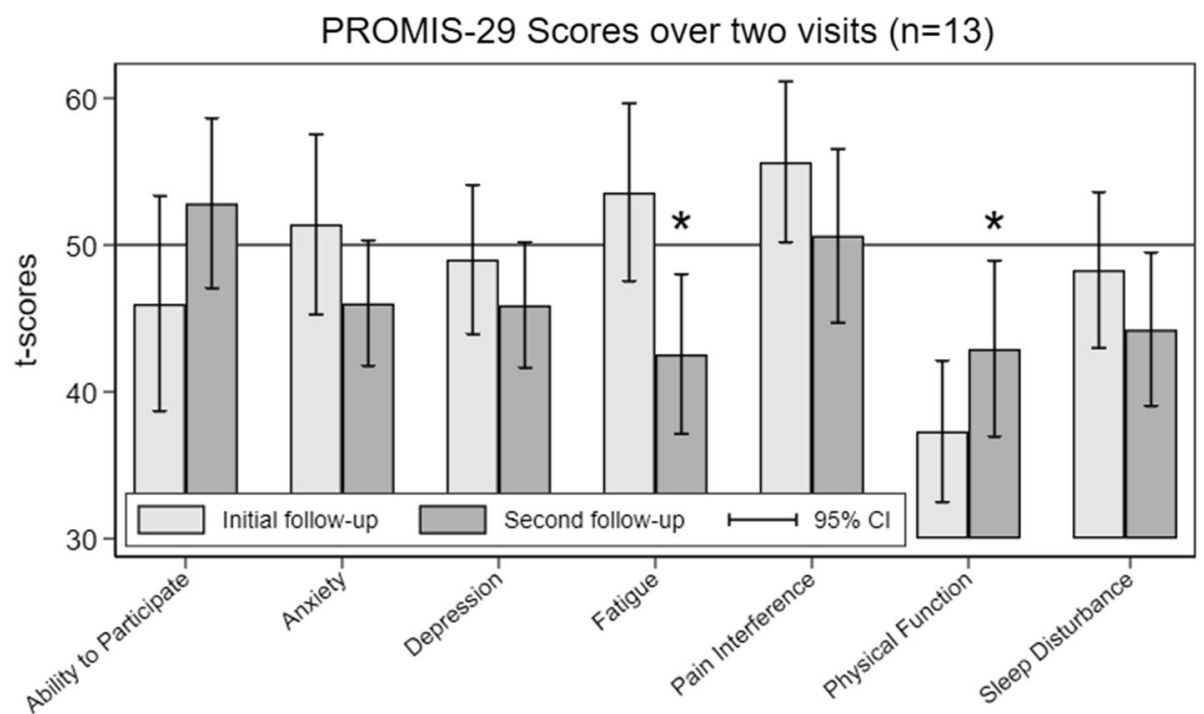

Domain
We have attempted to mitigate this limitation through subset analysis. Finally, our practice of collecting PROs in EGS patients in clinic was significantly disrupted after March of 2020 secondary to the COVID-19 pandemic, thus limiting our ability to expand our sample size and continue longitudinal follow-up. However, since the COVID-19 pandemic might in and of itself be expected to impact on elements of quality of life, this does limit the impact of confounding due to factors not directly related to recover from EGS.

These limitations notwithstanding, this evidence may inform future research and clinical efforts. While the evidence base on PROs in EGS is still in its infancy, we have provided some preliminary data suggesting target domains for investigation and demonstrated the feasibility of data collection, even without additional resources such as registrars. Logical next steps should include PROMIS measurement in a broader cohort of EGS patients. Given the wide range of disease states and operations encompassed by EGS, further exploration into the populations at highest risk for poor HRQoL outcomes is warranted. Our finding that laparotomy patients only reported detriments in the same two domains as the overall cohort was surprising. Nonetheless, there is likely to be a cohort of severely ill patients who would benefit most from attention to PROs. More robust longitudinal follow-up will also be useful. While we were only equipped to administer this instrument in clinic, one could easily conceive of a system in which patients complete a HRQoL instrument via internet from home at time points beyond initial follow-up. Correlation between PROs and other outcomes, such as return to work or development of new chronic disability, would be informative. Eventually, the development of interventions to target high-impact PRO domains is likely to be useful.

\section{Conclusion}

Though patients reported outcomes on par with the US average in several domains, we demonstrated room for improvement in the domains of pain interference and physical function. While positive changes over a relatively short period of time are encouraging, consideration should be given to patient perceptions of illness and lifestyle impact when managing EGS patients.

Author contributions JSH, DNH, and MJS were involved in conceptualization and study design. JSH, ALB, DNH, MJS, and KC were involved in data collection. JSH, DNH, and MJS were involved in data analysis and interpretation. JSH, ALB, LWM, and DNH were involved in drafting of manuscript. KC, JPB, PMR, BMB, and MJS were involved in critical review and revision.

Funding This project received no funding.

\section{Declaration}

Conflict of interest No authors have conflicts to declare.

\section{References}

1. Jones RS, Stukenborg GJ (2017) Patient-reported outcomes measurement information system (PROMIS) use in surgical care: a scoping study. J Am Coll Surg 224:245-254.e241 
2. Plsek P (2001) Institute of medicine crossing the quality chasm a new health system for the 21st century. National Academy Press, Washington

3. Lavallee DC, Chenok KE, Love RM et al (2016) Incorporating patient-reported outcomes into health care to engage patients and enhance care. Health Aff 35:575-582

4. National Quality Forum (2013) Patient reported outcomes (PROs) in performance measurement

5. PROMIS. Health Measures. Available at: http://www.healthmea sures.net/explore-measurement-systems/promis

6. Donovan JL, Hamdy FC, Lane J et al (2016) Patient-reported outcomes after monitoring, surgery, or radiotherapy for prostate cancer. N Engl J Med 375:1425-1437

7. Barocas DA, Alvarez J, Resnick MJ et al (2017) Association between radiation therapy, surgery, or observation for localized prostate cancer and patient-reported outcomes after 3 years. JAMA 317:1126-1140

8. Tully PJ, Baker RA, Turnbull DA et al (2009) Negative emotions and quality of life six months after cardiac surgery: the dominant role of depression not anxiety symptoms. J Behav Med 32:510

9. Vella MA, Warshauer A, Tortorello G et al (2020) Long-term functional, psychological, emotional, and social outcomes in survivors of firearm injuries. JAMA Surg 155:51-59

10. Haider AH, Herrera-Escobar JP, Al Rafai SS et al (2020) Factors associated with long-term outcomes after injury: results of the functional outcomes and recovery after trauma emergencies (FORTE) multicenter cohort study. Ann Surg 271:1165-1173

11. Land SR, Kopec JA, Julian TB et al (2010) Patient-reported outcomes in sentinel node-negative adjuvant breast cancer patients receiving sentinel-node biopsy or axillary dissection: national surgical adjuvant breast and bowel project phase III protocol B-32. J Clin Oncol 28:3929-3936

12. Pusic AL, Matros E, Fine N et al (2017) Patient-reported outcomes 1 year after immediate breast reconstruction: results of the mastectomy reconstruction outcomes consortium study. J Clin Oncol 35:2499-2506

13. Pucciarelli S, Del Bianco P, Efficace F et al (2011) Patient-reported outcomes after neoadjuvant chemoradiotherapy for rectal cancer: a multicenter prospective observational study. Ann Surg 253:71-77

14. Hedrick TL, Harrigan AM, Thiele RH et al (2017) A pilot study of patient-centered outcome assessment using PROMIS for patients undergoing colorectal surgery. Support Care Cancer 25:3103-3112

15. Andersen JR, Aasprang A, Karlsen T-I et al (2015) Health-related quality of life after bariatric surgery: a systematic review of prospective long-term studies. Surg Obes Relat Dis 11:466-473
16. Efthymiou V, Hyphantis T, Karaivazoglou K et al (2015) The effect of bariatric surgery on patient HRQOL and sexual health during a 1-year postoperative period. Obes Surg 25:310-318

17. Raoof M, Näslund I, Rask E et al (2015) Health-related qualityof-life (HRQoL) on an average of 12 years after gastric bypass surgery. Obes Surg 25:1119-1127

18. Hawn MT, Itani KM, Giobbie-Hurder A et al (2006) Patientreported outcomes after inguinal herniorrhaphy. Surgery 140:198-205

19. Havens JM, Peetz AB, Do WS et al (2015) The excess morbidity and mortality of emergency general surgery. J Trauma Acute Care Surg 78:306-311

20. Shafi S, Aboutanos MB, Agarwal S et al (2013) Emergency general surgery: definition and estimated burden of disease. J Trauma Acute Care Surg 74:1092-1097

21. Ghaferi AA, Birkmeyer JD, Dimick JB (2009) Variation in hospital mortality associated with inpatient surgery. $\mathrm{N}$ Engl J Med 361:1368-1375

22. Gale SC, Shafi S, Dombrovskiy VY et al (2014) The public health burden of emergency general surgery in the United States: a 10-year analysis of the nationwide inpatient sample-2001-2010. J Trauma 77:202-208

23. Scott JW, Olufajo OA, Brat GA et al (2016) Use of national burden to define operative emergency general surgery. JAMA Surg 151:e160480

24. Detmar SB, Muller MJ, Schornagel JH et al (2002) Health-related quality-of-life assessments and patient-physician communicationa randomized controlled trial. JAMA 288:3027-3034

25. Cella D, Riley W, Stone A et al (2010) The patient-reported outcomes measurement information system (PROMIS) developed and tested its first wave of adult self-reported health outcome item banks: 2005-2008. J Clin Epidemiol 63:1179-1194

26. Cook KF, Jensen SE, Schalet BD et al (2016) PROMIS measures of pain, fatigue, negative affect, physical function, and social function demonstrated clinical validity across a range of chronic conditions. J Clin Epidemiol 73:89-102

27. Ware Jr JE, Sherbourne CD (1992) The MOS 36-item short-form health survey (SF-36): I. Conceptual framework and item selection. Med Care 30(6):473-483

28. Sauaia A, Moore EE, Crebs JL et al (2012) Evidence level of individual studies: a proposed framework for surgical research. J Trauma Acute Care Surg 72:1484-1490

Publisher's Note Springer Nature remains neutral with regard to jurisdictional claims in published maps and institutional affiliations. 